\title{
PSYCHOLOGICAL STRESS AMONG UNIVERSITY STUDENTS IN THE SULTANATE OF OMAN
}

\author{
الضغوط النفسية للى طلبة الجامعة في سلطنة عمان \\ أحمد بن عبدالله بن محمد البارحي \\ Ahmed Abdullah Albarh ${ }^{1 *} \&$ Siti Kholijah Kassim ${ }^{2}$ \\ ${ }^{1}$ Ph.D. Candidate in Education at International Islamic University Malaysia (IIUM); \\ Albarhi77441@gmail.com \\ ${ }^{2}$ Assoc. Prof. Dr. in Education at International Islamic University Malaysia (IIUM); \\ Sitikholijahkassim@iium.edu.my \\ ${ }^{*}$ Corresponding author
}

\begin{abstract}
This qualitative study discusses psychological pressures related to university study among students of Sultan Qaboos University in the Sultanate of Oman, and the problem lies in the university student's suffering from undergraduate study pressures, which may lead to a lower academic level, which causes him a kind of tension, anxiety and frustration, and he may be forced later To leave his university studies and not pursue it. The study aimed to discuss the impact of psychological stress on university students, both academically and psychologically, and to analyze the proposals of the study sample to reduce their psychological and academic stress. The researcher used the qualitative descriptive approach to collect information using the interview as a tool for the study. The interview questions consisted of two axes, the first axis: the sources of various psychological pressures that affect the university student, and the second axis: the status of students 'academic performance in light of psychological stress and the role of academic counseling. The tool applied to a sample of (10) students enrolled in the Student Counseling Center. The findings revealed that: that university students suffer from academic psychological pressures that ranged from high to medium level, most of the pressures centered around the accumulation of study materials, the frequent examinations, the inability to manage time and reconcile all subjects, determine priorities, and arrange goals. The results also indicated that there is a strong relationship between the psychological stress that the university student suffers from, and his low level of achievement. The study sample members suggested that the University's Student Counseling Center conduct training courses and workshops for university students in order to help them get rid of pressure and raise their achievement levels.
\end{abstract}

Keywords: academic pressures, university students, student counseling center

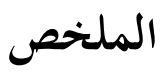

ناقشت هذه الدراسة النوعية الضغوط النفسية المتعلقة بالدراسة الجامعية لدى طلبة جامعة السلطان قابوس بسلطنة

عمان، وتكمن المشكلة في معاناة الطالب الجامعي من ضغوط دراسية في المرحلة الجامعية، والتي قد تؤدي إلى تدني 
مستواه الدراسي، مما يسبب له نوعاً من التوتر والقلق والإحباط، وقد يضطر لاحقا إلى ترك دراسته الجحامعية وعدم

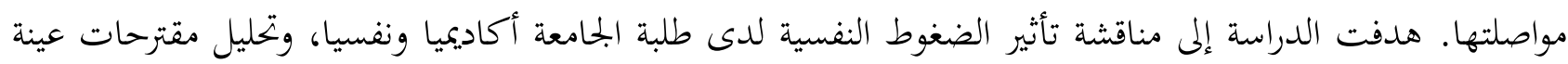

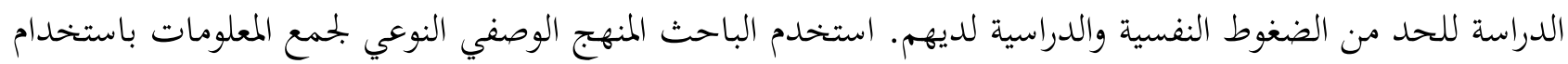

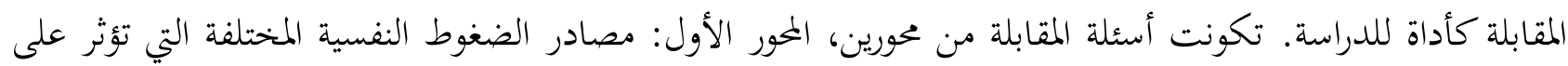

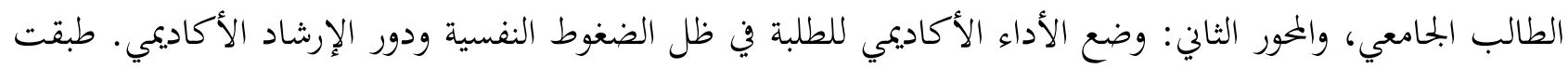
الأداة على عينة مكونة من (10) طلاب من طلبة جامعة السلطان قابوس الملتحقين بمركز الإرشاد الطلابي بالجامعة.

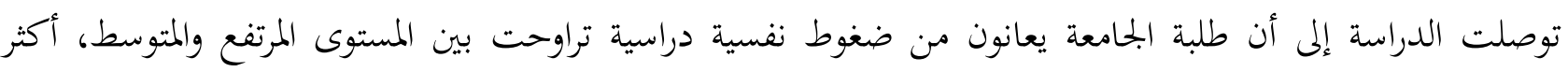

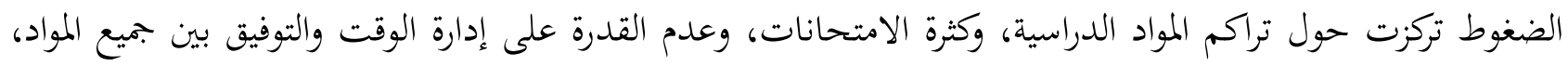

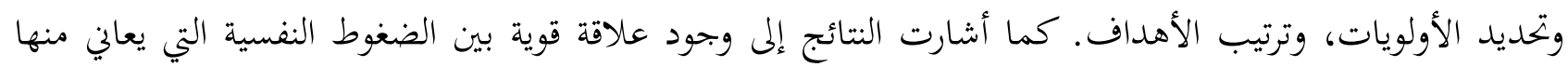

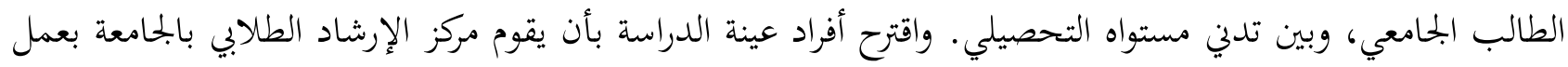

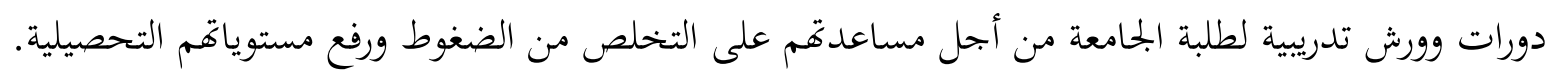
الكلمات المفتاحية: الضغوط الدراسية، طلبة الجامعة، مركز الإرشاد الطلابي

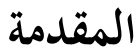

تعد الضغوط بكافة أنواعها نتاج للتقدم الفكري والحضاري المتسارع، وذلك نتيجة للتطور التكنولوجي في كافة بحالات

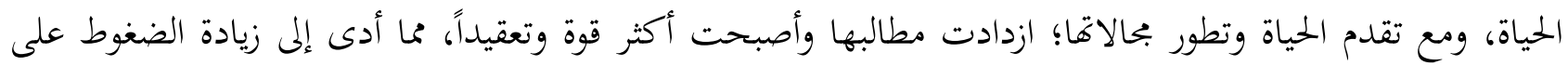

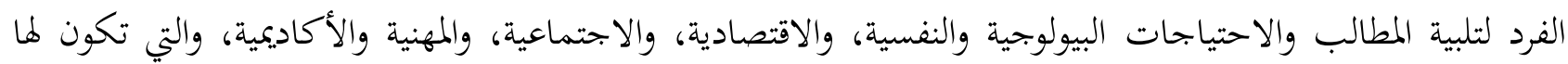

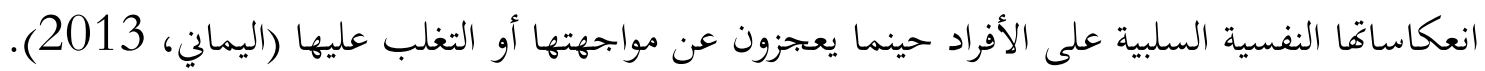
وتؤثر الضغوط على حياة الأفراد أياً كان نوعها، بحيث بتعلهم في حالة من عدم الاستقرار النفسي والاجتماعي، لاسيما

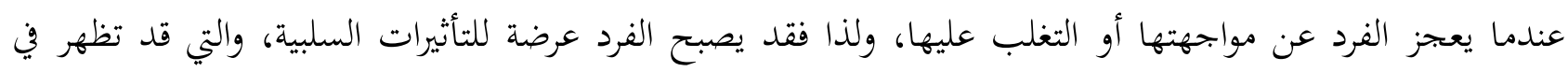

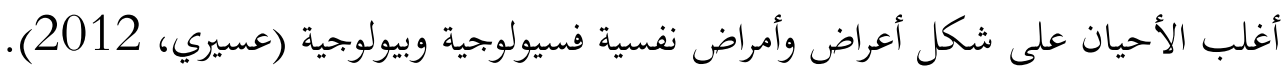
وتعتبر الضغوط النفسية من أكثر الضغوط التي تؤثر على الأفراد في كافة بحالات حياقم، وتجعلهم في حالة من التوتر

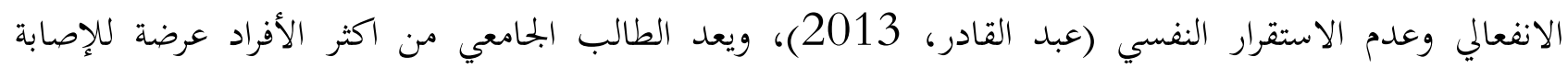

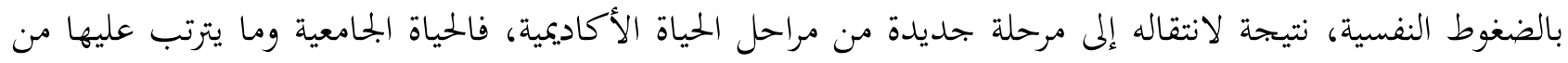

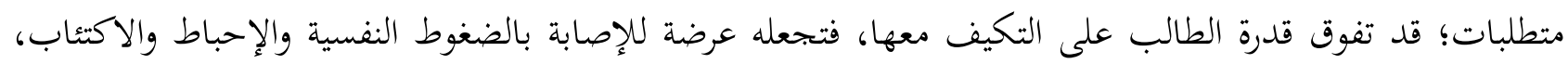

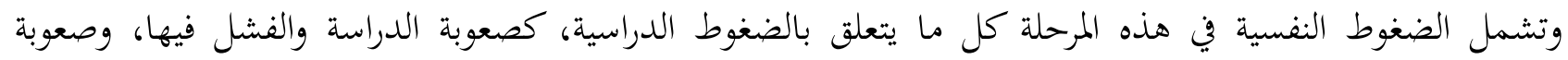

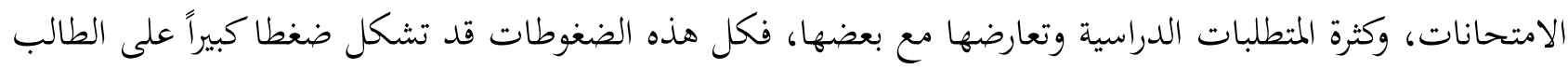


الجامعي، وبتعله عرضة للإصابة بالإحباط والفشل الدراسي، مما يؤثر على مستواه الأكاديمي ودافعيته لمواصلة الدراسة الجامعية. (عشعش، ونكله عرضة لإصابة 2017).

\section{مشكلة الدراسة}

تكمن مشكلة الدراسة في أن الطالب الجامعي يكون عرضة للإصابة بالضغوط النفسية، نتيجة لانتقاله إلى مرحلة جديدة

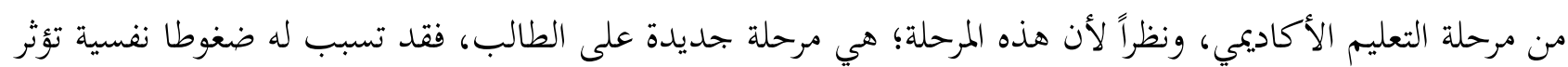

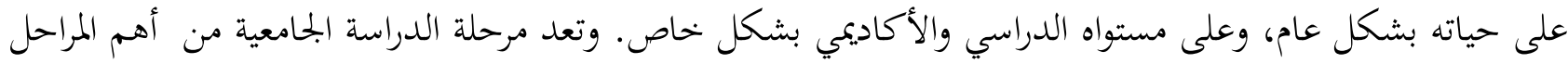
في حياة الطالب، فهي مرحلة انتقالية، تنقل الطالب من مقاعد الدراسة إلى بناء المستقبل المهني والأسري فيما بعد، ونظرا

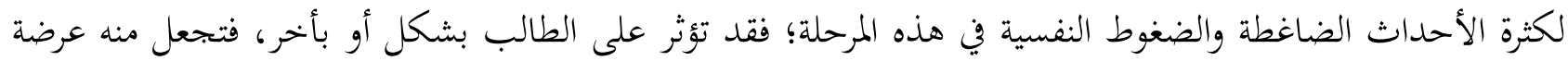

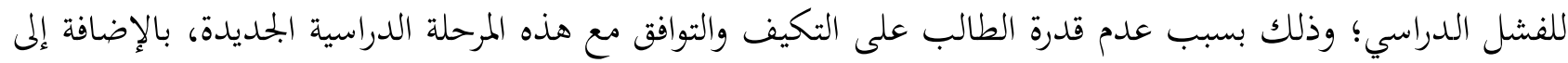

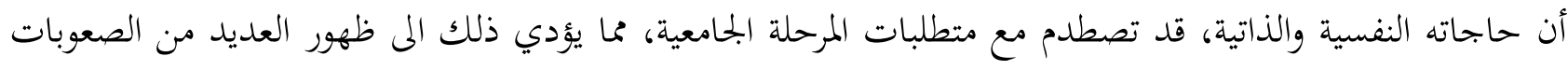

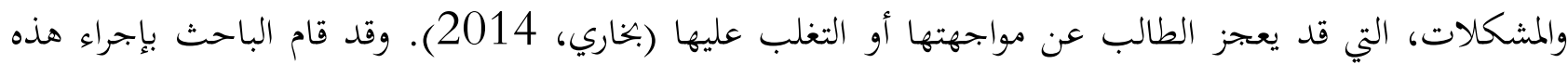
الدراسة للتعرف على الضغوط النفسية الدراسية التي يتعرض لها الطالب الجامعي، في مراحل الدراسة الجامعية في سلطنة عمان. (- n

وعليه فإن مشكلة الدراسة تتلخص في السؤال التالي: "ما أكثر الضغوط النفسية الدراسية تأثيراً على الطالب الجامعي

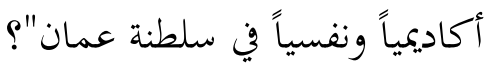

أهداف الدراسة

أ. مناقشة تأثير الضغوط النفسية لدى طلبة الجامعة أكاديميا ونفسيا. ب. تحليل مقترحات عينة الدراسة للحد من الضغوط النفسية والدراسية لديهم.

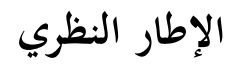

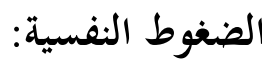

تعرف الضغوط النفسية على أغا: حالة من التوتر الانفعالي، نتيجة لاستجابة الفرد لموقف معين، يتسم بالأحداث

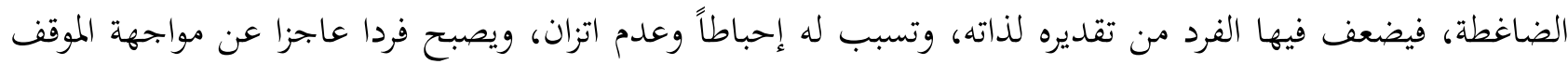

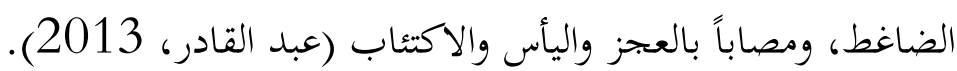

وتعرف بأها: بحموعة الصعوبات المباشرة وغير المباشرة، التي يواجهها الطالب الجامعي، وقد ينتج عنها العديد من

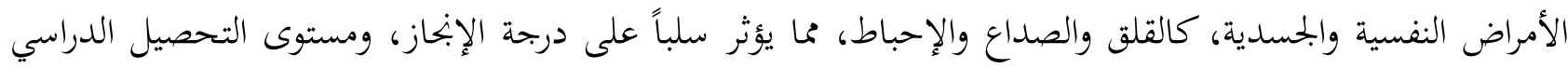

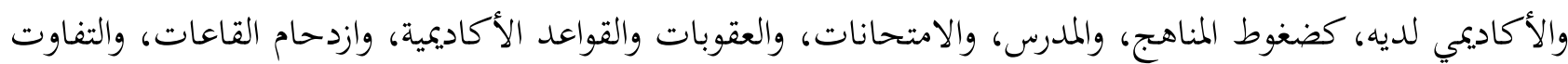


الحضاري، والنشاطات الطلابية، والواجبات المنزلية، وكثرة المتطلبات الدراسية، وصعوبة إدارة الوقت وتعارض المواد

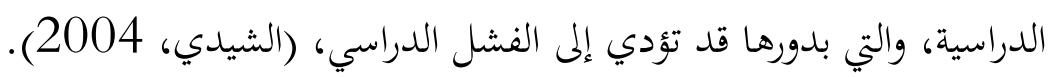

ويرى الباحث أن الضغط النفسي الدراسي الذي يصاب به الطالب، يجعله في حالة من التوتر النفسي وعدم الاستقرار،

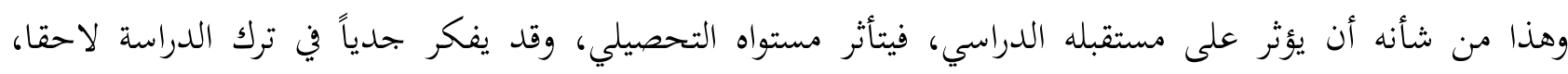

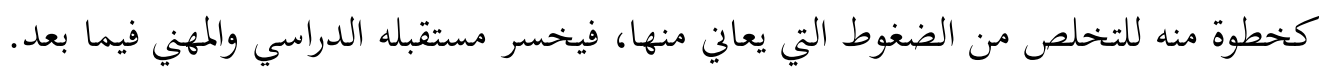
مصادر الضغط النفسي يمكن إجمال مصادر الضغوط النفسية الطلابية في ثلاث نقاط أساسية، وذلك كما ذكرها (FIMAIN,1986) في دراسته التي أجراها على (111) طالباً وتتمثل في: 1. الانزعاج: ويتمثل في عدم تقبل التلميذ لزملائه، وصعوبة في قدرته على تكوين الاصدقاء، وصعوبة قدرته على التعلم، وانخفاض معدل تحصيله الدراسي، وعدم استغلال وقت فراغه. 2. المشكلات الدراسية والاجتماعية: وتتضمن بعض المشكلات التي يشملها مصدر الانزعاج سالفة الذكر. 3. العلاقات السيئة: وتتمثل في صعوبة التعامل مع المعلم، والنظام الثابت (الروتين) داخل الفصل الدراسي، ومشاعر الوحدة النفسية. وأضاف (الطريري، 1994) أن المشكلات الشخصية كالهروب، والمقاومة، وانخفاض تقدير الذات، والمشكلات الدراسية

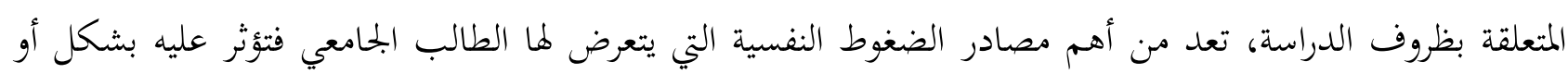
بأخر.

أنواع الضغوط: ذكر عبد القادر، (213) أن الضغوط تنقسم إلى نوعين رئيسيين وهما: أ. الضغط النفسي الإيجابي: هو عبارة عن التغيرات والتحديات التي تفيد نمو المرء وتطوره (كالتفكير مثلا)، وهذا النوع النغاء

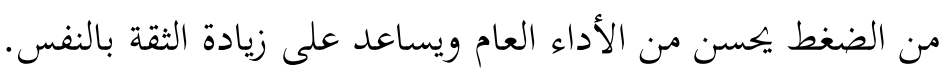
ب. الضغط النفسي السبي: أو الضيق فهو عبارة عن الضغوطات التي يواجهها الفرد في العائلة أو العمل أو في

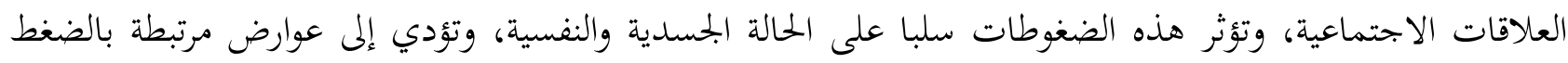

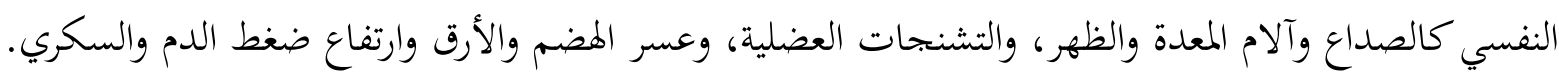

\section{بعض النظيات المفسرة للضغوط النفسية} نظرية هانز سيلي: يرى سيلي أن الضغوط النفسية تتكون لدى الفرد عندما يمر بضغوط متكررة، فتسببه لها إحباطات

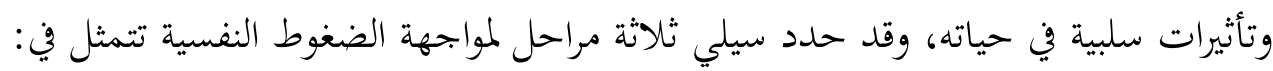


أ. مرحلة ردة الفعل: وهي خط الدفاع الأول عند الشعور بالتهديد أو الضغط، وتظهر في صورة أعراض فسيولوجية ونفسية كالتوتر وزيادة إفراز الهرمونات.

ب. مرحلة المقاومة: وتعتمد هذه المرحلة على قدرة الفرد على التكيف مع شدة الضغط والعوامل المصاحبة له، ومدى

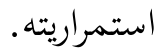

ت. مرحلة الإغاك: في هذه المرحلة تنخفض قدرة الفرد على المواجهة، ويستنفذ جميع طاقاته وقدراته التكيفية فيصبح عرضة للأمراض النفسية والجحدية، وقد يصل لحالات الموت في بعض الأحيان (البسطامي، 2013).

النظرية التفاعلية (لازاورس وفولكمان): يشير لازاورس وفولكمان إلى أن الضغط النفسي ينشأ نتيجة العملية التفاعلية بين مطالب البيئة وإمكانيات الفرد، وحينما تكون تلك المطالب تفوق إمكانيات الفرد وطاقاته التكيفية على مواجهة الضغوط؛ يصبح الفرد عرضة للإصابة بالضغوط النفسية والاهيار. ويرى أصحاب هذه النظرية أن الفرد يقوم بعملية التقييم المعرفي لمطالب البيئة والإمكانيات التي يمتلكها من خلال ثلاث مراحل أساسية وهي:

أ. التقييم الأولي: ويقصد بها تقييم الفرد للموقف الضاغط وهل هو سلبيا أو إيجابيا وهل يشكل خطرا عليه أو لا. ب. التقييم الثانوي: وهنا يقوم الفرد بتحديد إمكانياته وقدراته لمواجهة الموقف الضاغط، كما يقوم بتحديد الطرق والاستراتيجيات الأنسب لمواجهة الموقف الضاغط

ت. إعادة التقييم: ويقصد بها تقييم الطرق والأساليب التي استخدمها الفرد لمواجهة الموقف، ومعرفة الإيجابيات والسلبيات للطرق والأساليب التي تم استخدمها، كذلك معرفة مدى حاجتها للتغيير أو التعديل أو التطوير (البسطامي، .2013

النظرية السلوكية: يرى أصحاب هذه النظرية أن الضغط النفسي ينتج نتيجة تفاعل الفرد مع البيئة، ويؤكد أصحاب هذه النظرية أن هذا التفاعل ضروري وحتمي، وأن الضغط الناتج عن ذلك التفاعل هو أمر طبيعي، ولكن حينما يحدث اصطدام بين الفرد والبيئة نتيجة ذلك التفاعل، ولا يستطيع الفرد تحمله، ويفوق قدرته في التحمل على المواجهة، ينشأ الضغط النفسي لدى الفرد، ويرى بعض أصحاب هذه النظرية أن الضغط ينشأ نتيجة تفاعل ثلاثة عناصر مع بعضها، الفرد والسلوك والبيئة، كما يشير بعض السلوكيون إلى أن قدرة الفرد على مواجهة الضغوط، تعتمد على درجة فعالية الذات لديه والتي ترتبط بالبيئة الاجتماعية للفرد، ومدى إدراك الفرد لقدراته وإمكانياته في مواجهة الضغوط (ساعد،

ويرى الباحث أن النظريات السابقة ركزت على أن الضغوط النفسية تؤثر على الفرد نفسيا وجسديا، وأنه يجب على الفرد أن يحشد طاقاته وقدراته الدفاعية ليتمكن من مواجهة الضغوط والمواقف الضاغطة، ويؤكد الباحث على ضرورة المقاومة الفردية لضغوطات الحياة النفسية، من أجل أن يتمكن الفرد من مواصلة حياته، وتحقيق أهدافه في الحياة، بعيدا عن الإحباط والمشاعر السلبية التي قد تعوق تقدمه في الحياة. 


\section{الدراسات السابقة}

دراسة (النادر والقضاة، 2013)، بعنوان " مصادر الضغط النفسي لدى طلبة كلية التربية الرياضية وطلبة الكليات الأخرى في كل من جامعة مؤتة وجامعة البلقاء التطبيقية وعلاقتها ببعض المتغيرات (دراسة مقارنة)". هدفت الدراسة إلى معرفة مصادر الضغط النفسي لدى طلبة كلية الرياضة وعلاقتها بكل من متغيرات الجنس والمستوى الدراسي والمعدل التراكمي، ثم مقارنتها بباقي الطلبة من الكليات المختلفة. اعتمدت الدراسة على المنهج الوصفي المقارن واستخدمت المتاف

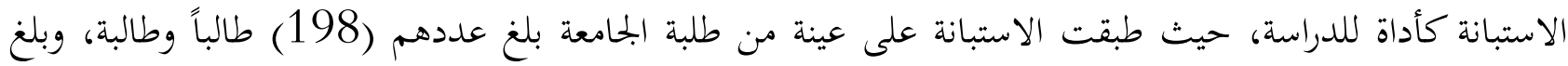

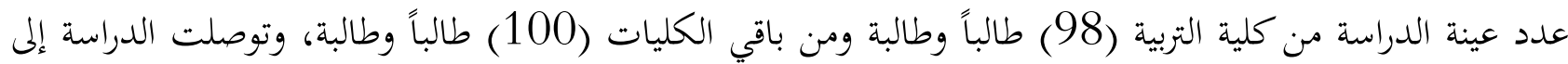

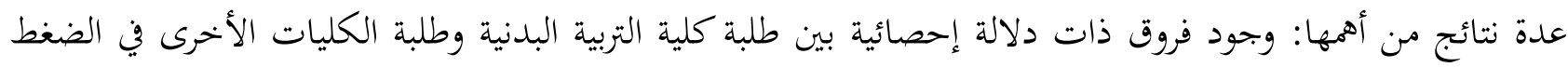

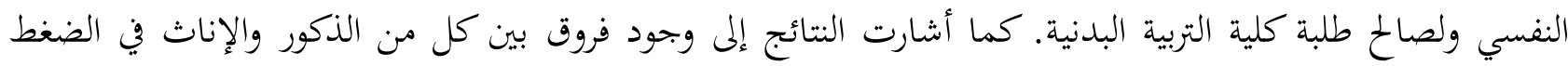
النفسي تعزى للمعدل التراكمي.

دراسة (كومار وبهوكار،2013) ، بعنوان: مستوى الضغوط النفسية واستراتيجيات التأقلم لدى طلاب الكلية". هدفت الدراسة المى معرفة مستويات الضغط النفسي واستراتيجيات التعامل مع الطلبة الجامعيين من تخصص التربية المهنية وتخصص المهن المندسية. واشتملت عينة الدراسة على (60) طالباً وطالبه من التخصصين في الهند. واستخدم الباحث

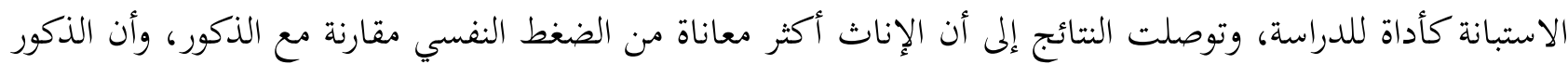

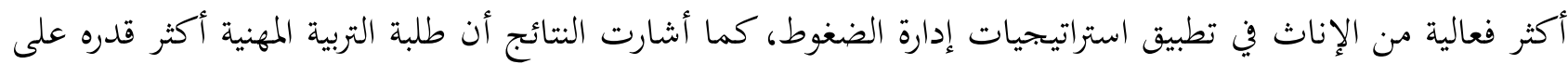

$$
\text { إدارة الضغوط من طلبة تخصص المهن الدراسية. }
$$

دراسة البيرقدار، (2011) بعنوان "مستوى الضغط النفسي ومصادره لدى طلبة كلية التربية في جامعة الموصل". وهدفت الدراسة الى التعرف على مستوى الضغط النفسي ومصادره لدى طلبة كلية التربية في جامعة الموصل، وبلغت

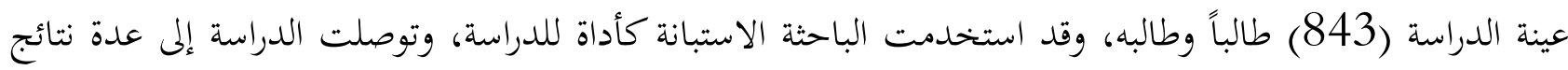

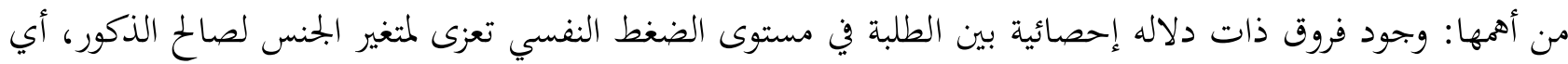

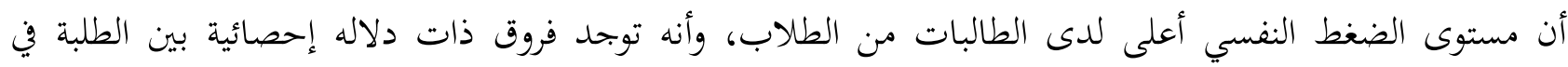
مستوى الضغط النفسي لصالخ التخصص العلمي. دراسة الزيود، (2006) بعنوان "استراتيجيات التعامل مع الضغوط النفسية لدى طلبة جامعة قطر وعلاقتها ببعض

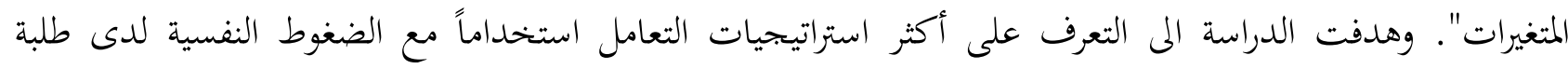

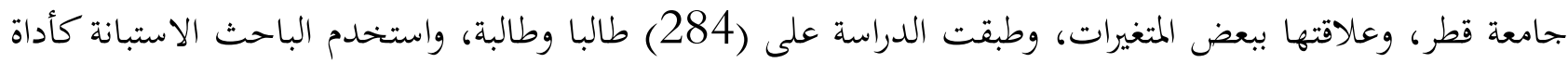

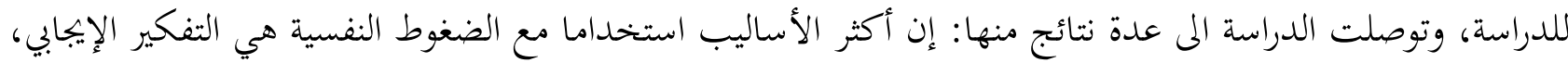

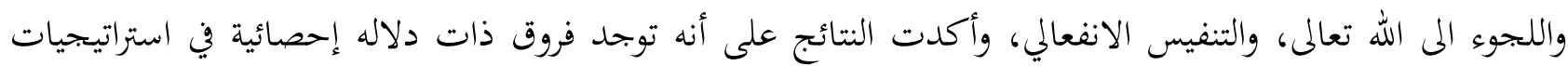


التعامل مع الضغوط النفسية لدى الطلبة تعزى لمتغير الجنس، بينما لا توجد فروق ذات دلاله إحصائية في استراتيجيات

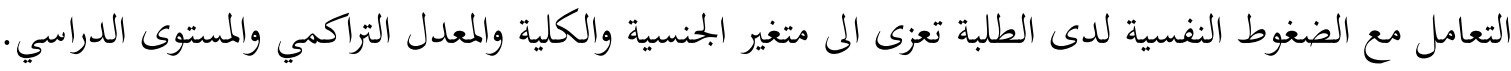

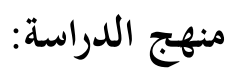

اتبعت هذه الدراسة المنهج الوصفي الكيفي (دراسة حاله نوعية)، حيث انه المنهج الملائم للتعرف على الضغوط النفسية

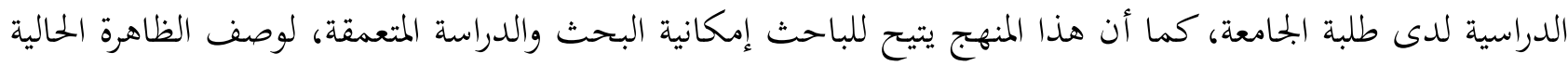

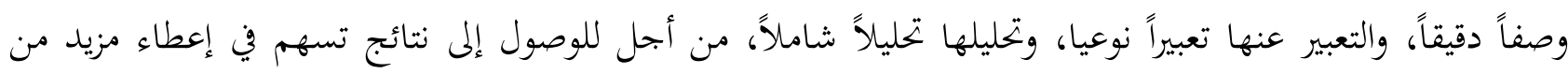
الحلول والمقترحات والتوصيات في هذا البمال.

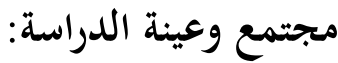

يتألف بحتمع الدراسة من الطلاب الملتحقين بمركز الإرشاد الطلابي بحامعة السلطان قابوس حيث بلغ عددهم (603)

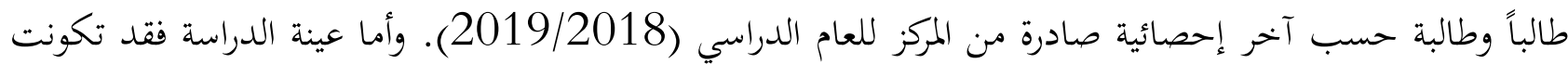

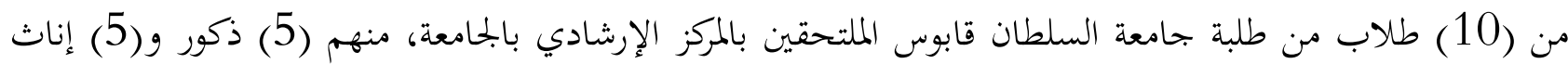
من كليات مختلفة وبتخصصات مختلفة وبسنوات دراسية متفاوتة، تم اختيارهم بالطريقة القصدية العمدية وفق لمتغيرات ديمغرافية معينة وهي (الجنس، الكلية، السنة الدراسية).

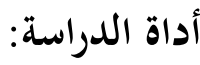

استخدم الباحث المقابلة كأداة رئيسية للدراسة، وذلك من أجل الحصول على البيانات والمعلومات المتعلقة بعينة الدراسة،

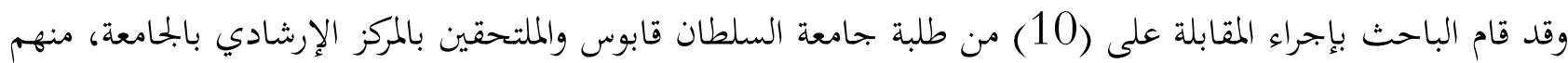
(5) طالبات، و(5) طلاب، وذلك بعد أخذ الأذن من المسؤولين بالمركز، وموافقة الطلبة بإجراء المقابلة معهم.

\section{أداة الدراسة في صورتها الأولية}

قام الباحث بإعداد أسئلة المقابلة بناء على أسئلة الدراسة وأهدافها، حيث تكونت أسئة المقابلة في صورتا الأولية من جزئين: الجزء الأول: البيانات الأولية لأفراد عينة الدراسة: - المئ

الجزء الثاني: ويتكون هذا الجزء من محور واحد، يتضمن بحموعة من الأسئلة الفرعية وهو: محور مصادر الضغوط النفسية

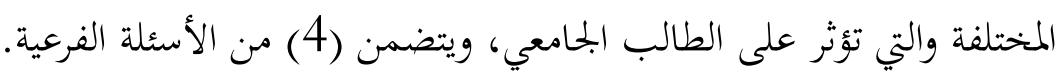
الصدق الظاهري لأسئلة المقابلة: تم التحقق من الصدق الظاهري لأسئلة المقابلة من خلال عرضها على لجنة من المحكمين بلغ عددهم (7) محكمين 
وذلك لقياس مدى صدق أسئلة المقابلة من حيث قدرتا على قياس الهدف التي وضعت من أجله، ومدى دقة صياغتها اللغوية، وارتباطها بالمور الذي تنتمي إليه، وبعد الاطلاع على ملاحظات المحكمين قام الباحث بتعديل ما يلزم من عبارات، سواء كان التعديل بالحذف أو إعادة الصياغة أو إضافة بعض المحاور.

\section{أسئلة المقابلة في صورتها النهائية:}

بعد إجراء التعديلات المقترحة، قام الباحث بوضع أسئلة المقابلة في صورتا النهائية، حيث تكونت أسئلة المقابلة في صورقا النهائية من جزئيين:

$$
\text { الجزء الأول: ويتضمن البيانات الأولية عن عينة أفراد الدراسة }
$$

الجزء الثاني: ويتكون من محوريين رئيسيين، ويتضمن كل محور بحموعة من الأسئلة الفرعية، وهي على النحو التالي: المحور الأول: مصادر الضغوط النفسية المختلفة والتي تؤثر على الطالب الجامعي، ويتضمن (3) أسئلة فرعية، والمحور الثاني: وضع الأداء الأكاديمي للطلبة في ظل الضغوط النفسية ودور الإرشاد الأكاديمي، ويتضمن سؤالين فرعيين.

\section{صدق وثبات أداة الدراسة:}

لاستخراج دلالات الصدق والثبات لأداة الدراسة (المقابلة)، قام الباحث بتحديد أفراد العينة، ثم التواصل معهم شخصيا من أجل أخذ الأذن منهم بإجراء المقابلة، كما قام الباحث أيضاً بالاتفاق المسبق مع أفراد عينة الدراسة، في تحديد وقت وزمن المقابلة حسب ما يناسب الطالب أو الطالبة، ومراعاة للمصداقية بشكل أكبر قام الباحث بأخذ الأذن من العينة بتسجيل المقابلة عبر التسجيل الصوتي ليتمكن الباحث بعدها من تحليل البيانات بشكل دقيق، وذلك بعد أن تعهد الباحث لأفراد عينة الدراسة بأن التسجيل الصوتي لن يستخدم إلا لغرض البحث العلمي، ثم قام الباحث بتفريغ المقابلات من التسجيل الصوتي إلى التحليل الكتابي، وإرساها إلى أفراد عينة الدراسة للتأكد من صحة إجاباهم، تمهيدا لتحليل البيانات بشكل صحيح للوصول إلى نتائج أكثر مصداقية وواقعية. نتائج الدراسة:

النتائج المتعلقة بالمحور الأول: مصادر الضغوط النفسية المختلفة التي تؤثر على الطالب الجامعي: عرض نتيجة السؤال الأول:

نص السؤال: ما أكثر الضغوط النفسية الدراسية التي يعاني منها الطالب الجامعي؟ بعد تحليل نتائج أسئلة المقابلة؛ تبين للباحث أن جميع المستجوبين العشرة يعانون من ضغوطات نفسية دراسية، تراوحت أغلبها بين المستوى المرتفع والمتوسط، وأن هذه الضغوطات أثرت عليهم أكاديميا وتحصيليا، وأدت إلى الخفاض مستواهم الدراسي، وأشارت أحدى الطالبات؛ إلى أن هذه الضغوطات كانت تؤثر عليها في فترة الامتحانات بشكل كبير، مما

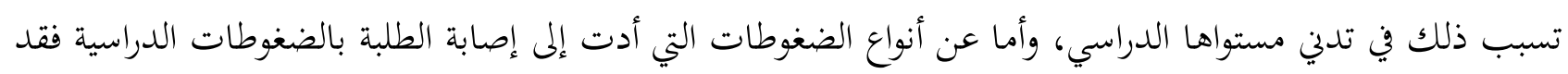


تنوعت كما ذكرها المستجوبين، حيث أشار ثمانية من المستجوبين إلى أغم يعانون من ضغوطات نفسية دراسية، أغلبها

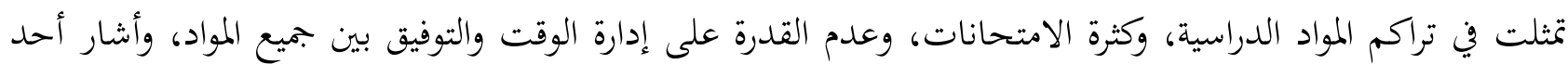

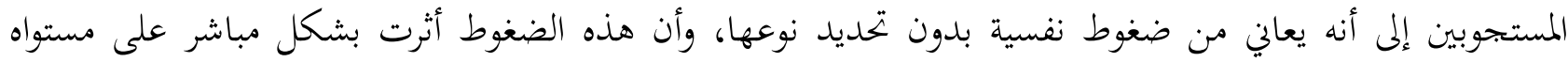

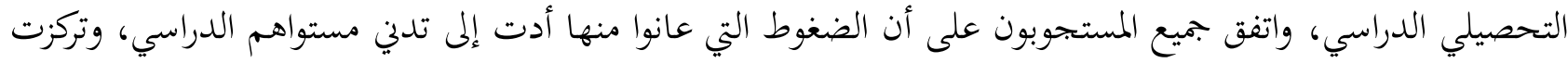

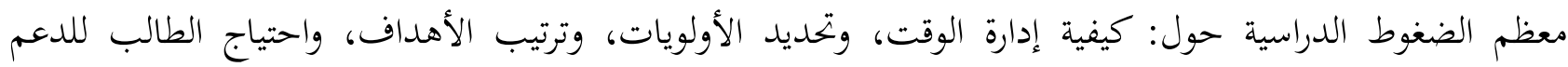
المعنوي المستمر.

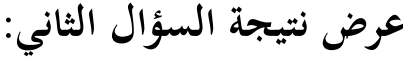

نصّّ السؤال الثاني: هل توجد علاقة بين الضغوط النفسية الأسرية وبين تفكير الطالب في عدم إكمال الدراسة أو تركها؟ بعد أن قام الباحث بتحليل نتائج المقابلة، توصل إلى أن جميع المستجوبون قد أشاروا إلى تأثير العلاقة القوية بين الضغوط

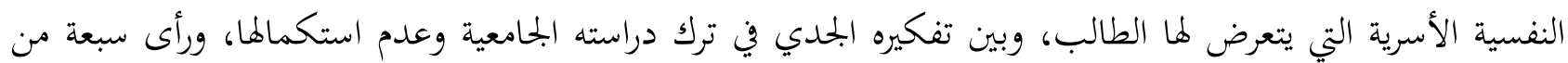
المستجوبين أن الأسرة هي العامل الأساسي الذي يساعد الطالب على بحاحه أو فشله في دراسته، فإذا كان الجحو الأسري مشحون بالتوتر، والضغوطات النفسية السلبية؛ أن يخفض دافعية الطالب لمواصلة الدراسة، وربما يفكر جديا في تركها

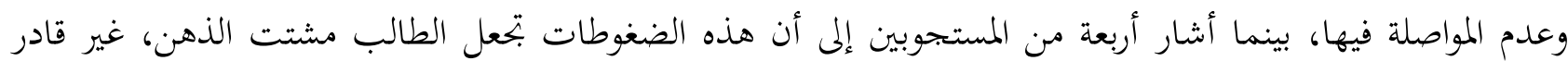
على التركيز، فيلجأ لأساليب الهرب والانسحاب، كالانسحاب من الجامعة وترك الدراسة، وأما أثنان من المستجوبين رأوا أن الضغوط النفسية تؤثر على الفرد في جميع حياته، ولكنها ليست بالضرورة تصل بالطالب إلى مرحلة ترك درابك دراسته المامعية وعدم المبالاة بها.

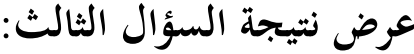

نصّ السؤال الثالث: هل يعاني الطالب الجامعي من الضغط النفسي المرتبط بالمستقبل الوظيفي؟ يتبين للباحث بعد تحليل أسئلة المقابلة، أن جميع المستجوبين اتفقوا على أها توجد ضغوط لدى الطلبة في هذه المرحلة تتعلق بالمستقبل الوظيفي، وأشار تسعة من المستجوبين إلى أن القلق في هذه المرحلة لدى الطلبة أمر طبيعي، وذلك لأنه

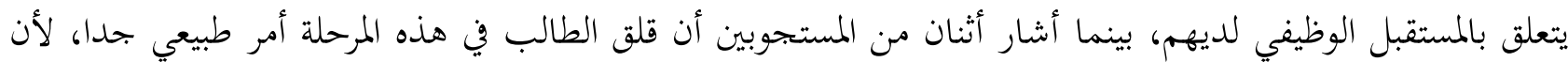

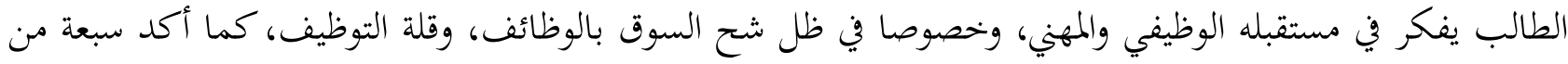

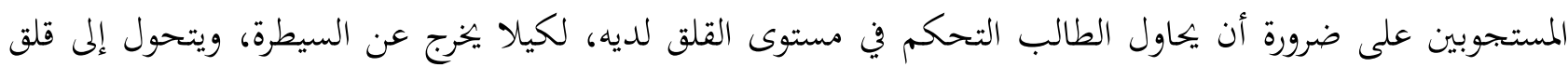

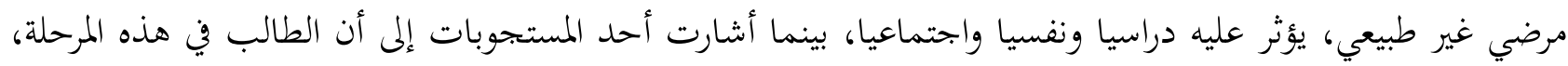

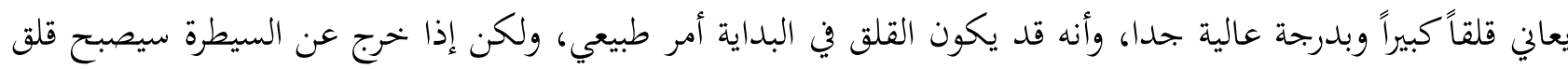
غير عادي وغير طبيعي، مما يجعل الطالب مشتت ذهنيا وفكريا. النتائج المتعلقة بالمحور الثاني: وضع الأداء الأكاديمي للطلاب في ظل الضغوط النفسية ودور الإرشاد 
نصَّ السؤال الأول على: هل توجد علاقة بين الضغوط النفسية التي يعاني منها الطالب وتدني مستواه الأكاديمي؟ بعد تحليل نتائج المقابلة مع عينة الدراسة؛ يتضح للباحث أن جميع المستجوبين اتفقوا على أنه توجد علاقة قوية جدا بين

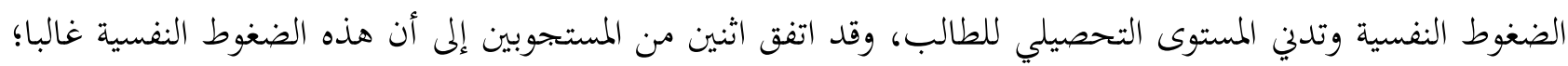

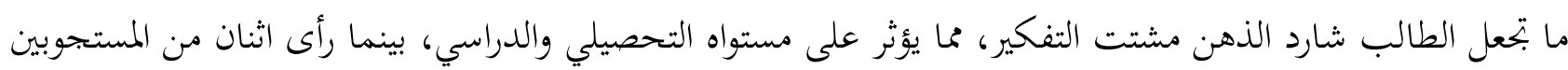

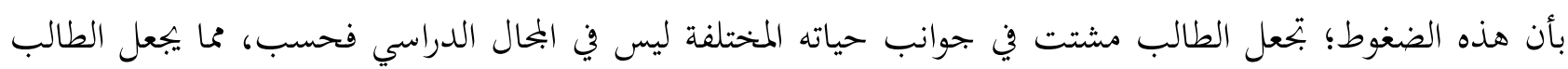

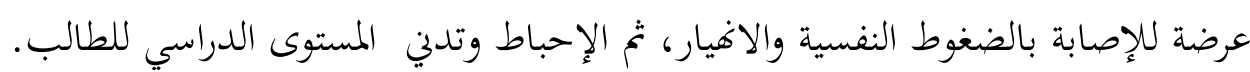

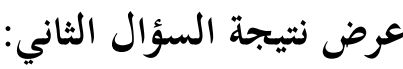

نصَّ السؤال الثاني على: كيف أسهم الإرشاد الطلابي الأكاديمي في تحسين مستوى الطالب التحصيلي؟ يتضح للباحث من خلال تحليل نتائج أسئلة المقابلة، أن الإرشاد الطلابي الأكاديمي الذي يتلقاه الطالب قد أسهم فعلياً

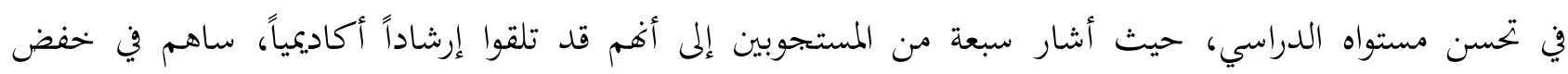

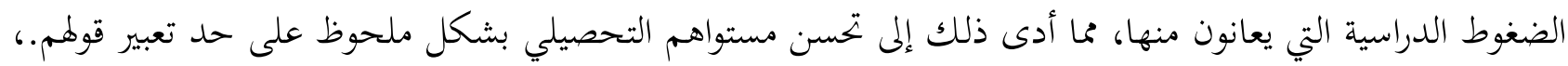

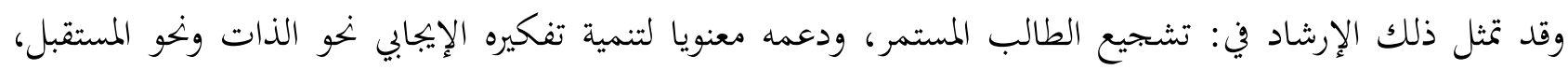

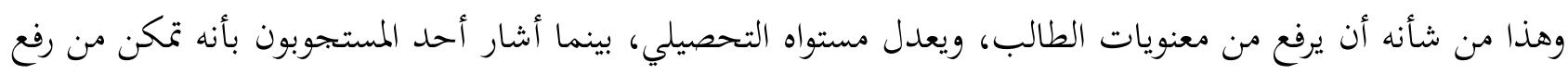

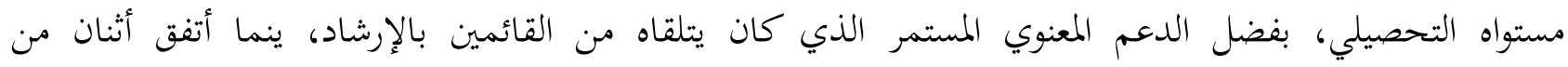

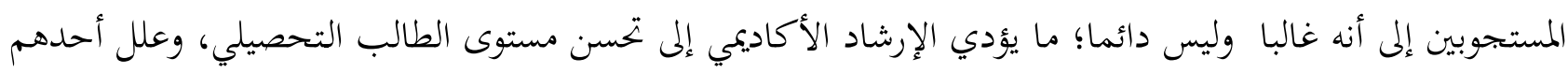

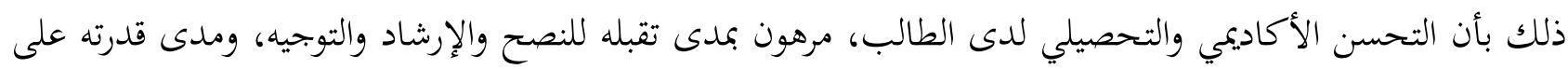
تقبل الواقع وتغيير معتقداته السلبية.

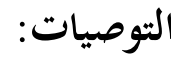
1. الاستعانة بمرشدين نفسين ومرشدين أكاديميين متخصصين من خارج الجامعة. 2. التحري عن الطلبة الذين يعانون من الضغوط النفسية وتقديم الخدمات الإرشادية لهم. 3. تفعيل دور مركز الإرشاد الطلابي بالجامعة، وذلك بعمل دورات ومحاضرات تستهدف الضغوط النفسية الأكاديمية والدراسية التي يتعرض لها الطالب الجامعي وطرق التخلص منها. 4. تواصل الجامعة أو مركز الإرشاد الطلابي بالجامعة مع أسرة الطالب في حالة التأكد من أن الطالب يعاني من مشاكل أسرية أثرت عليه أكاديميا وأدت إلى تدني مستواه الدراسي. 
قائمة المراجع:

البسطامي، سلام راضي أنيس (2013). مستوى إدارة استراتيجيات التكيف للضغوط النفسية لدى آباء الأطفال ذوي

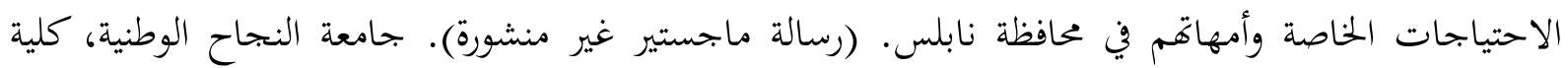
الدراسات العليا، نابلس. فلسطين.

البيرقدار، تنهيد عادل فاضل (2011). مستوى الضغط النفسي ومصادره لدى كلية التربية بجامعة الموصل. بحلة أبحاث كلية التربية، جامعة الموصل: العراق.

الزيود، نادر فهمي (2006). استراتيجيات التعامل مع الضغوط النفسية لدى طلبة جامعة قطر وعلاقتها ببعض المتغيرات. بحلة رسالة الخليج العربي. ع (99) (99).

ساعد، شفيق (2019). مصدر الضبط الصحي واستراتيجيات مواجهة الضغوط لدى المرضى المصابين بأمراض

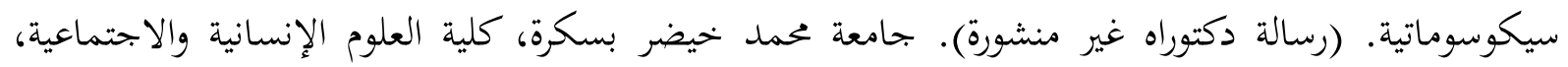
الجزائر.

عبد القادر، أبو بكر ساسي (2013). الضغوط النفسية وأساليب مواجهتها. بحلة روافد المعرفة. ع (2) جامعة الزيتونة: ليبيا.

عسيري، محمد عبدالله (2012). "الضغوط المهنية لدى معلمي المرحلة الابتدائية بمدينة تبوك بالمملكة العربية السعودية في ضوء بعض المتغيرات". بحلة جامعة الملك سعود للعلوم التربوية والدراسات الإسلامية: السعودية، 24 (3): .1032- 1001

عشعش، سارة لطفي وآخرون. (2017). أساليب مواجهة الضغوط النفسية وعلاقتها بالثفاؤل لدى عينة من طلاب

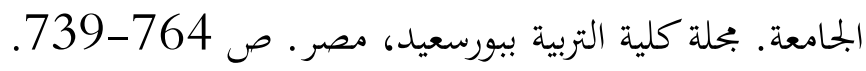

النادر، هيثم محمد عواد، وآخرون. (2013). مصادر الضغط النفسي لدى طلبة كلية التربية الرياضية وطلبة الكليات

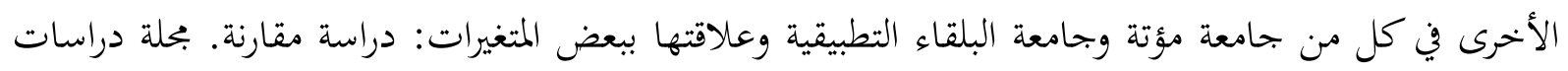

$$
\text { العلوم التربوية. الأردن. } 41 \text { (1): 192-203. }
$$

اليماني، عبد الرؤوف، والزعبي، نزار محمد (2013). استراتيجيات التعامل مع الضغوط النفسية لدى عينة من طلبة

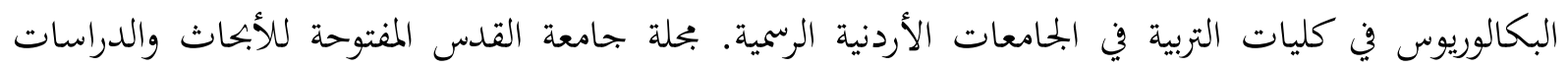

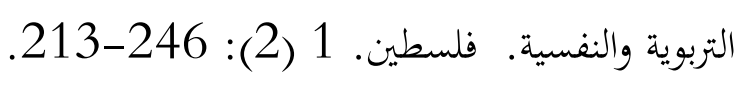




\section{ARABIC REFERENCES IN ROMAN ALPHABET}

Albistami, Salam Rady 'Unyus (2013). Mustawaa 'lidarat Aistiratijiaat Altakayuf Lildughut Alnafsiat Ladaa Aba' Al'atfal Dhwyi Alaihtiajat Alkhasat Wa'umahatihim fi Muhafazat Nablus. (Rsalat Majstayr Ghyr Minshurta). Jamieat Alnajah Alwataniati, Kuliyat Aldirasat Aleulya, Nablis. Filistin.

Albirqdar, Tanhid Eadil Fadil (2011). Mustawaa Aldaght Alnafsii Wamasadirih Ladaa Kuliyat Altarbiat Bijamieat Almawsili. Majalat 'Abhath Kuliyat Altarbiati, Jamieat Almwsl: Aleiraq.

Alzuyud, Nadir Fahmuy (2006). Aistiratijiaat Altaeamul Mae Aldughut Alnafsiat Ladaa Tlbt Jamieat Qatar Waealaqatiha Bibaed Almutaghayirati. Majalat Risalat Alkhalij Alearbi. E (99).

Saeid, Shafiq (2019). Masdar Aldabt Alsihiyi Waistiratijiaat Muajahat Aldughut Ladaa Almardaa Almusabin Bi'amrad Saykusumatiatin. (Rsalat Dukturah Ghyr Minshurta). Jamieat Muhamad Khaydr Biskrat, Kuliyat Aleulum Al'insaniat Walaijtimaeiati, Aljazayir.

Eabd Alqadir, 'Abu Bakr Sasi (2013). Aldughut Alnafsiat Wa'asalib Muajahataha. Majalat Ruafid Almaerifati. E (2) Jamieat Alzytwnt: Libia.

Easiri, Muhamad Eabdallh (2012). "Aldughut Almihniat Ladaa Muelimi Almarhalat Alaibtidayiyat Bimadinat Tbwk Bialmamlakat Alearabiat Alsaeudiat fi Daw' Bed Almutaghayirata". Majalat Jamieat Almalik Sueud Lileulum Altarbawiat Waldirasat Al'iislamiat: Alsaeudiati, 24 (3): 1001 - 1032.

Easheash, Sart Ltfy Wakharun. (2017). 'Asalib Muajahat Aldughut Alnafsiat Waealaqatiha Bialtafawul Ladaa Eayinat Min Tullab Aljamieati. Majalat Kuliyat Altarbiat Biburiseid, Misr. S 764-739.

Alnaadiru, Haytham Muhamad Eawad, Wakharawn. (2013). Masadir Aldaght Alnafsii Ladaa Tlbt Kuliyat Altarbiat Alriyadiat Watalabat Alkuliyat Al'ukhraa fi Kli Min Jamieat Mutat Wajamieat Albalqa' Altatbiqiat Waealaqatiha Bibaed Almutaghayirati: Dirasat Muqarinat. Majalat Dirasat Aleulum Altarbawiati. Al'urdunn. 41 (1): 192-203.

Alymani, Eabd Alrawuwf, Walzaebi, Nizar Muhamad (2013). Aistiratijiaat Altaeamul Mae Aldughut Alnafsiat Ladaa Eayinat Min Tlbt Albikaluryws fi Kuliat Altarbiat fi Aljamieat Al'urduniyat Alrasmiati. Majalat Jamieat Alquds Almaftuhat Lil'abhath Waldirasat Altarbawiat Walnafsiati. Filastin. 1 (2): 246-213 